\title{
RETRACTED ARTICLE: Learning an video-based message sharing system for large-scale smart vehicles
}

\author{
Hu Zhen-tao ${ }^{1} \cdot$ Zepeng Wang $^{2}$ (D) Peng Shu ${ }^{3}$ • \\ Xinyu Xiang ${ }^{4}$
}

Received: 19 December 2017 /Revised: 6 February 2018 /Accepted: 8 February 2018 /

Published online: 20 February 2018

(C) Springer Science+Business Media, LLC, part of Springer Nature 2018

The Editor-in-Chief has retracted this article [1], which was published as part of special issue "Multi-source Weak Data Management using Big Data", because its content has been duplicated from an unpublished manuscript authored by $\mathrm{N}$ Edna Elizabeth, V Hansini, R Hemapriya and S Kavitha without permission. In addition, there is evidence suggesting authorship manipulation and an attempt to subvert the peer review process.

Author Zepeng Wang stated on behalf of all co-authors that they agree to this retraction.

\section{References}

1. Zhen-tao, H., Wang, Z., Shu, P. et al. Learning an video-based message sharing system for large-scale smart vehicles. Multimed Tools Appl (2018). https://doi.org/10.1007/s11042$018-5760-8$

Electronic supplementary material The online version of this article (https://doi.org/10.1007/s11042-0185760-8) contains supplementary material, which is available to authorized users.

\section{Zepeng Wang}

1422617933@qq.com

1 College of Computer and Information Engineering, Henan University, Kaifeng, China

2 Department of CSIE, Hefei University of Technology, Hefei, China

3 State Grid Zhejiang Electric Power Research Institute, Hangzhou, China

4 State Grid Hangzhou Power Supply Company, Hangzhou, China 